\title{
EUMYCOTIC MYCETOMA DUE TO CURVULARIA SPECIES: A UNIQUE PRESENTATION
}

Sushruth G. Kamoji1 ${ }^{1}$, Jayashree Nayak², Malteshgouda N. Patil ${ }^{3}$

\section{HOW TO CITE THIS ARTICLE:}

Sushruth G. Kamoji, Jayashree Nayak, Malteshgouda N. Patil. "Eumycotic Mycetoma Due to Curvularia Species: A Unique Presentation". Journal of Evolution of Medical and Dental Sciences 2015; Vol. 4, Issue 11, February 05; Page: 1893-1895, DOI: $10.14260 /$ jemds/2015/274

Mycetoma is a chronic infection caused by different species of fungi and bacteria characterized by tumefication, discharging grains and draining sinuses, involving the skin, subcutaneous tissue and rarely bones. When the causative agent for Mycetoma is a fungus, it is termed as Eumycetoma and when it is caused by filamentous bacteria, it is termed as Actinomycetoma.[1] Mycetoma is endemic in India, Pakistan, parts of Africa, Central and South America and Indonesia.[2]

Here, we report a rare case of Eumycetoma due to Curvularia lunata with a unique presentation. [3] A 28 year old female farmer presented to our OPD in November 2012 with multiple discharging wounds over the left side of upper chest, back, shoulder and axilla of 8 years duration. The patient initially developed a single ulcer over left back about 8 years ago which healed with scarring but continued to develop more such lesions over the years. On examination, she had numerous nodules with discharging sinuses over her left torso. The discharge was sero sanguinous and there were intervening areas of hypopigmented and hyperpigmented scars. On palpation the local temperature was raised and the lesions were tender. Multiple axillary lymph nodes were enlarged, discrete and tender.

Radiograph of the chest was normal and Complete blood counts revealed anemia (4.5 gm\%), leukocytosis (13000/microlit) raised $\operatorname{ESR}(65 \mathrm{~mm}$ at 1 hour). The discharge from sinuses was subjected to Gram's stain, ZN stain and culture - sensitivity. Gram's stain showed gram positive cocci in clusters and culture showed growth of Staphylococcus aureus sensitive to vancomycin and clindamycin. Biopsy was sent for histopathology and tissue culture. Meanwhile patient was started on Inj Vancomycin. Histopathology of the nodule revealed diffuse inflammatory infiltrate with abundant vascular channels. It was a further 4 weeks before we could get the culture report. On Sabouraud's dextrose agar media (containing chloramphenicol without cycloheximide), black-colored colonies with white aerial hyphae were noted. Microscopically, lactophenol cotton blue wet mount of the colony showed erect, unbranched, septate, flexuous, brown-colored conidiophores, along with conidia. ${ }^{[4]}$ The conidia were smooth walled, olivaceous brown in color, four-celled with 3 septae and a larger sub-terminal cell. Thus, a diagnosis of Eumycetoma due to Curvularia lunata was reached. Hence, patient was started on oral Itraconazole $100 \mathrm{mg}$ twice daily.[5] The patient responded very well to the treatment with resolution of most of the nodules with scarring by the end of 6 months. Patient was followed up for over a year without any relapse.

\section{REFERENCES:}

1. Ahmed AO, Van Leeuwen W, Fahal A, Van de Sande W, Verbrugh H, Van Belkum A. Mycetoma caused by Madurella mycetomatis: A neglected infectious burden. Lancet Infect Dis 2004; 4: 566-74. 
2. Turiansky G. Eumycetoma (Fungal Mycetoma). emedicine from WebMD. http://emedicine.medscape.com/article/1090738-diagnosis.2009.

3. Janaki C, Sentamilselvi G, Janaki VR, Devesh S, Ajithados K. Eumycetoma due to Curvularia lunata. Mycoses 1999; 42: 345-6.

4. Benoit, H.C. and Mathur, S.B. (1970) Identification of species of Curvularia on rice seed. Proceedings International Seed Testing Association, 6, 6-10.

5. Garg A, Sujatha S, Garg J, Parija SC, Thappa DM. Eumycetoma due to Curvularia lunata. Indian journal of Dermatology, Venereology and Leprology 2008; 74 (5): 515-516.

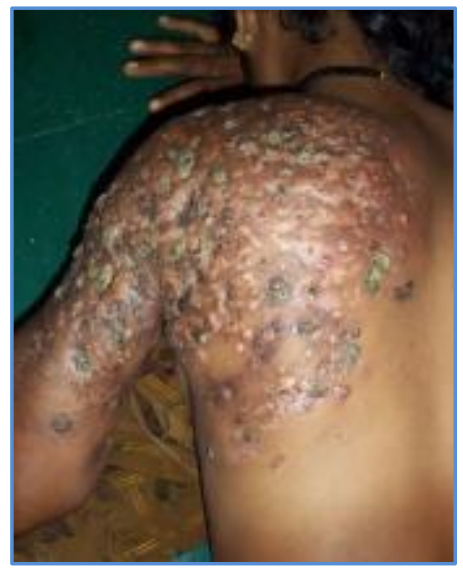

Fig. 1

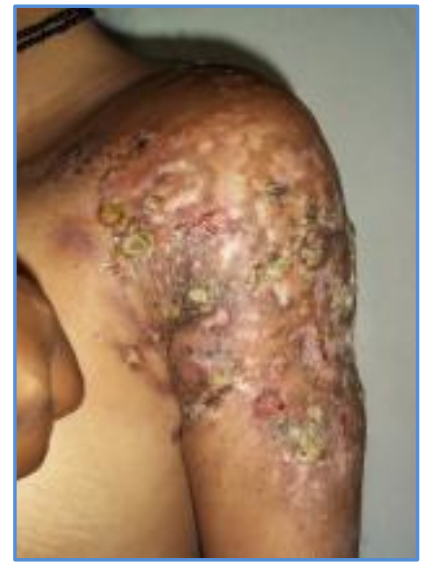

Fig. 2

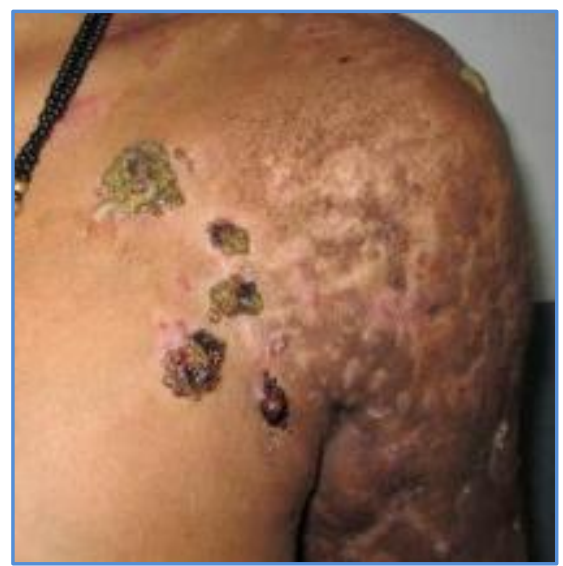

Fig. 3

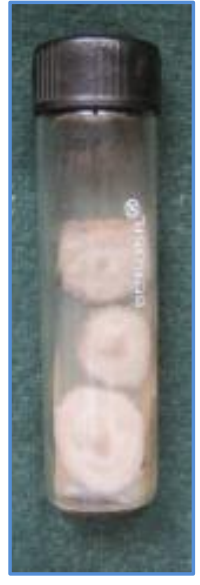

Fig. 4

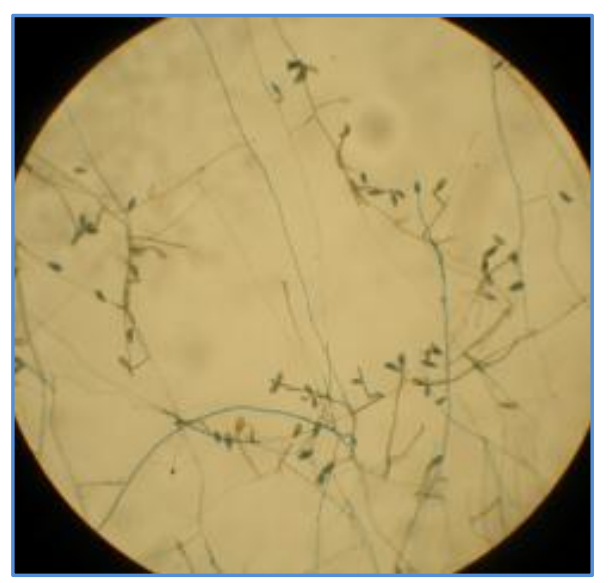

Fig. 5

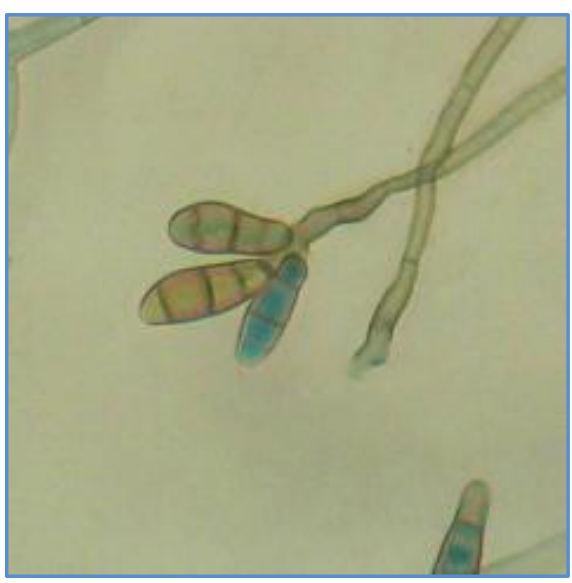

Fig. 6 


\section{LETTER TO THE EDITOR}

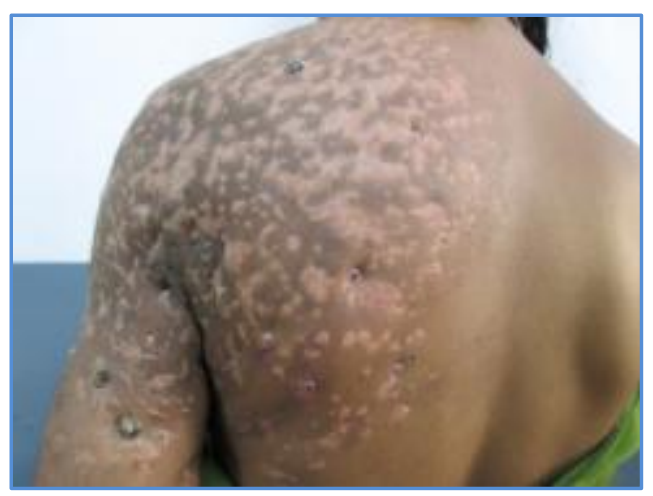

Fig. 7

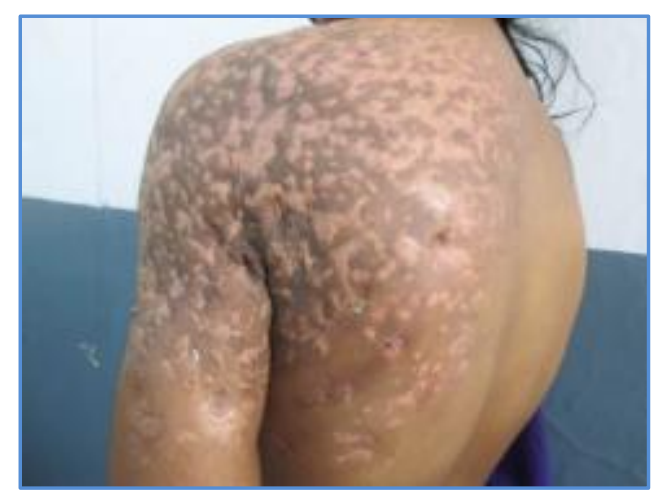

Fig. 8

\section{AUTHORS:}

1. Sushruth G. Kamoji

2. Jayashree Nayak

3. Malteshgouda N. Patil

\section{PARTICULARS OF CONTRIBUTORS:}

1. Resident, Department of Dermatology, Belgaum Institute of Medical Sciences, Belgaum.

2. Assistant Professor, Department of Dermatology, Belgaum Institute of Medical Sciences, Belgaum.

3. Professor \& HOD, Department of Dermatology, Belgaum Institute of Medical Sciences, Belgaum.

\section{NAME ADDRESS EMAIL ID OF THE CORRESPONDING AUTHOR:}

Dr. Sushruth G. Kamoji,

Flat No. 204, Doctor's Quarters,

Opp. HDFC Bank,

Civil Hospital Campus,

Belgaum, Karnataka.

E-mail: drsushruthk@yahoo.co.in

Date of Submission: 23/12/2014.

Date of Peer Review: 24/12/2014.

Date of Acceptance: 27/01/2015.

Date of Publishing: 05/02/2015. 